\title{
The Role of the Androgen Receptor Signaling in Breast Malignancies
}

\author{
PANAGIOTIS F. CHRISTOPOULOS*, NIKOLAOS I. VLACHOGIANNIS*, \\ CHRISTIANA T. VOGKOU and MICHAEL KOUTSILIERIS \\ Department of Experimental Physiology, School of Medicine, \\ National and Kapodistrian University of Athens, Athens, Greece
}

\begin{abstract}
Breast cancer $(\mathrm{BrCa})$ is the most common malignancy among women worldwide, and one of the leading causes of cancer-related deaths in females. Despite the development of novel therapeutic modalities, triple-negative breast cancer $(T N B C)$ remains an incurable disease. Androgen receptor $(A R)$ is widely expressed in $\mathrm{BrCa}$ and its role in the disease may differ depending on the molecular subtype and the stage. Interestingly, AR has been suggested as a potential target candidate in TNBC, while sex hormone levels may regulate the role of $A R$ in $B r C a$ subtypes. In the presence of estrogen receptor $\alpha(E R a)$, AR may antagonize the ER $\alpha$-induced effects, whereas in the absence of estrogens, AR may act as an ER $\alpha$ mimic, promoting tumor. Thus, depending on the $\mathrm{BrCa}$ microenvironment, both agonists and antagonists of the AR have been suggested as therapeutic approaches. Herein, we review the role of AR signaling in $\mathrm{BrCa}$ and the molecular cross-talk mechanisms with other molecules/pathways, as well as its therapeutic implications in the different subtypes of the disease.
\end{abstract}

Breast cancer $(\mathrm{BrCa})$ is the most common solid tumor among women with an annual incidence of 123 new cases $/ 100,000$ females according to the United States Cancer Statistics and 252.710 estimated new cases in the U.S. in 2017. Despite significant progress made in therapeutics during the last 2

This Article is freely accessible online.

*These Authors contributed equally to the study.

Correspondence to: Dr. Michael Koutsilieris, Department of Experimental Physiology, Medical School, National and Kapodistrian University of Athens, 75 Micras Asias, Goudi-Athens, 115 27, Greece. Tel: +30 2107462597, Fax: +30 2107462571, e-mail:mkoutsil@med.uoa.gr

Key Words: Breast cancer, androgen receptor (AR), estrogen receptor alpha $(\mathrm{ER} \alpha)$, triple-negative breast cancer (TNBC), review. decades, BrCa still has a poor prognosis with 5-year survival rates of metastatic disease reaching to $26 \%$ only. $\mathrm{BrCa}$ is the second leading cause of death among female cancers with 40,610 estimated deaths in the U.S. expected in 2017 (1).

Breast cancer comprises a heterogeneous group of diseases with variable course and outcome. Currently, $\mathrm{BrCa}$ is subclassified into distinct molecular subtypes named: normal breast like, luminal A/B, HER-2 related, basal-like and claudinlow $(2,3)$. Estrogen receptor (ER), progesterone receptor (PR) and HER2 have long been established as useful prognostic and predictive biomarkers. Hormonal therapy in ER and PR positive tumors (4), as well as the use of monoclonal antibodies in HER2 over-expressing tumors (5) have shown promising results, however overall survival of metastatic disease remains relatively low (1). To date, androgen receptor (AR) has been suggested to play a key role in breast cancer biology in certain disease subgroups $(6,7)$.

$\mathrm{AR}$ is expressed in all stages of breast cancer (in-situ, primary and metastatic disease) and its contribution to the progression of disease may differ depending on the stage (8). Overall, AR expression among patients with breast cancer has been estimated at approximately $77 \%$ and varies significantly among molecular subtypes of $\mathrm{BrCa}(9)$. Human observational studies have associated AR with better outcome in $\mathrm{ER}^{+}$ tumors, but this positive effect may be lost in ER- tumors (10, 11). Of interest, AR expression correlates with better clinicopathological features in the most aggressive form of $\mathrm{BrCa}$, triple-negative breast cancer (TNBC) (12). AR seems to have distinct roles in disease development and progression depending on the tumor's hormonal environment and specifically upon relative levels of androgens and estrogens.

The historically used androgens together with antiandrogens, Selective AR Modulators (SARMs) and Androgen Receptor antagonists constitute valuable options for the treatment of specific disease subpopulations. In the past decade, a wealth body of studies have focused on AR targeting along with hampering major signaling pathways 
implicated in $\mathrm{BrCa}$ biology in combinational therapeutic approaches. Herein we review the experimental and clinical evidence investigating the role of $\mathrm{AR}$ in $\mathrm{BrCa}$ development, progression and metastasis, as well as exploring its therapeutic efficacies in the different subgroups of the disease. Special emphasis has been given on the AR-induced signaling in $\mathrm{BrCa}$ and the molecular cross talk mechanisms with other molecules/pathways that may hold promising therapeutic implications.

\section{The Androgen-AR Axis in Normal and Cancerous Breast Tissue}

While the estrogen-ER $\alpha$ axis constitutes the predominant regulator of female breast development, androgens also play a significant role through their balanced antagonism with estrogens (13). The main circulating active androgen in females is testosterone, which is synthesized both in the ovaries and the adrenal glands, as well as by peripheral conversion of the inactive androgen precursors such as dehydroepiandrosterone (DHEA) (14). In the breast tissue, testosterone is converted either to dihydrotestostone (DHT) by $5 \alpha$-reductase or to $17 \beta$-estradiol (E2) by aromatase and can function as an AR or ER $\alpha$ agonist respectively, thus having a dichotomous effect on breast development $(8,15)$. Studies have shown that testosterone is converted to E2 under estrogen deprivation, but is preferentially metabolized into DHT when both hormones are present at physiological levels, thus hampering the E2-induced effects $(16,17)$. Maintenance of this balance ensures the physiological response of the mammary gland depending on the hormonal needs and the menopausal status.

Although data remain conflicting, AR is indispensable for normal breast growth. AR-knock-out mice showed reluctant ductal extension and branching, as well as markedly reduced epithelial cell proliferation in the breast tissue (18), whereas transcriptional inactivation of AR in another in vivo model led to accelerated mammary growth and increased number of terminal end buds, an effect that was reversible with DHT treatment (19). Abnormal cell proliferation could be partially attributed to reduced insulin-like growth factor-1 receptor (IGF-1R) signaling via cross-talk mechanisms (impaired MAPK and cyclin D1 activation), underlining the importance of a functional AR for the physiological regulation of breast development $(18,20)$.

The addressed effects of exogenous androgen treatment on breast tissue proliferation are also controversial (21). Androgens have been shown to inhibit growth of breast tissue probably via interfering with both basal and estrogen-induced proliferation of AR-expressing breast cancer cell lines and epithelial breast cells $(21,22)$. However, the molecular pathways underlining this inhibitory effect are rather unclear due to the ability of testosterone to act both as AR and ER $\alpha$ agonist. As discussed above, the effect of androgens on breast growth is dependent upon relative levels of estrogens. In the vein to shedding more light on this balance, studies have investigated breast growth under extreme states of androgen signaling. Congenital adrenal hyperplasia, which is characterized by extremely high levels of androgens, associates with inhibition of normal breast growth (15), whereas AR knock-out in vivo shows incomplete mammary gland development (18). Moreover, during the menstrual cycle, breast cell proliferation is maximal during the luteal phase, when testosterone levels are reduced and estrogen levels are highest, whereas during the follicular phase, where testosterone levels are stable and estrogens are significantly reduced, breast cell apoptosis is increased $(8,23)$. In general, evidence shows that although androgens have an inhibitory effect on breast tissue development in the presence of estrogens, AR-induced signaling is compulsory for normal breast tissue growth.

\section{Polymorphisms and Post-translational Modifications of the AR in Breast Cancer}

Nowadays cancer is considered as a genetic disease characterized by both inter-tumoral and intra-tumoral (spatial and temporal) genetic heterogeneity. As such, it is conceivable that in the vein of personalized therapeutics, focus has been turned into studying the genetic background of the distinct breast cancer subtypes in selective population subgroups (24).

The gene encoding for the $A R$ is located on the $\mathrm{X}$ chromosome, having a length of more than $90 \mathrm{~kb}$ and is subjected to alternative splicing modifications giving rise to various isoforms. The role of the most common splice variant, V7, has recently been explored in breast cancer tissues. AR V7 was associated with androgen deprivation resistance and was expressed in more than $50 \%$ of $\mathrm{BrCa}$ cases. Moreover, treatment with enzalutamide, a non-steroidal anti-androgen, led to AR V7 up-regulation suggesting a potential mechanism of acquired resistance to anti-androgen therapy (25).

Variable length of a CAG repeat in exon 1 of the $A R$ gene constitutes a functional polymorphism with potential prognostic significance. However, the association between number of triplet-repeats and risk of $\mathrm{BrCa}$ development is rather unclear (26). The initial study by Giguere $e t$ al. showed that smaller numbers of CAG repeats were protective against $\mathrm{BrCa}$ development (27). In contrast, the majority of studies that followed showed either positive or no correlation between the CAG repeat length and $\mathrm{BrCa}$ risk (28), whereas, a metaanalysis incorporating 6,788 cases of breast cancer patients and 7,648 controls showed that increased number of repeats is protective against $\mathrm{BrCa}$ (29). The controversies regarding a clear correlation between CAG repeats and risk of $\mathrm{BrCa}$ may be attributed to the lack of an established threshold clearly defining the length of high or low CAG repeats (i.e. 21 repeats). Furthermore, population-specific diversity may lead 
to distinct frequency patterns (28). Recently, Gottlieb et al. described an alternative approach analyzing laser capture micro-dissected tissue specimens from $\mathrm{BrCa}$ patients using next generation sequencing in contrast to previous studies that stratified peripheral blood samples. As expected, high intratumoral genetic heterogeneity regarding the CAG repeats was revealed, while the preferential selection of 18-25 CAG repeat length was associated with breast cancer. In the same study, it was shown that shorter CAG repeats may be protective against breast cancer risk (26).

The role of AR genotypes in response to endocrine therapy has also been explored. In this vein it has been suggested that certain AR diplotype variants may be associated with longer breast-cancer free survival in response to tamoxifen (30).

$\mathrm{AR}$ is also subjected to post-translational processing, predominantly phosphorylation at various sites, serine, threonine and tyrosine residues, which are of major importance for its functions $(31,32)$. The existence of a series of possible phosphorylation sites of the $\mathrm{AR}$ has also been proven in vivo, the majority of which are located in the N-terminal of the AR protein. Their role, however, remains unclear (31). In a recent paper, Ren et al. explored the value of two specific phosphorylation sites at $\operatorname{Ser}(\mathrm{P})-213$ and $\operatorname{Ser}(\mathrm{P})-650$, as prognostic factors for $\mathrm{BrCa}$ using immunohistochemistry. AR$\operatorname{Ser}(\mathrm{P})-213$ was found significantly increased both in the nucleus and the cytoplasm of breast cancer specimens compared to benign ones, whereas, AR-Ser(P)-650 was significantly decreased (33). It seems that different phosphorylation patterns for AR may apply in benign and cancerous breast tissue. More studies are warranted to shed more light into the role of the distinct post-translational modifications of AR in the pathophysiology of the disease.

\section{AR Signaling in Anti-estrogen-resistant Breast Cancer}

Hormonal therapy using Selective Estrogen Receptor Modulators (SERMs) -like Tamoxifen (Tam) and Raloxifen are the first choice of targeted therapeutics in pre-menopausal women with both early or metastatic disease (34). However, up to $30 \%$ of patients show resistance to tamoxifen either from the beginning (de novo resistance) or during the course of treatment (acquired resistance) (35). In the vein of understanding the mechanisms of Tam-resistance, focus has turned into the investigation of potential cross talks with other molecules and signaling pathways such as HER-2 (36), IGF1R (37) and MAPK (38). Currently and despite its central role in $\mathrm{BrCa}$ pathogenesis, data exploring the role of $\mathrm{AR}$ signaling in Tam-resistant breast tumors are relatively limited.

Expression micro-arrays and qRT-PCR analysis of cancerous breast tissues have shown increased mRNA levels of AR in Tam-resistant tumors compared to Tam-responsive ones (39). Furthermore, in vitro studies of AR-overexpressing
MCF-7 cells showed increased resistance to Tam, with Tam having AR-agonistic effects. Treatment with the antiandrogen bicalutamide restored Tam-sensitivity, alluding to the underlying interaction between AR and ER $\alpha$ signaling as a key mechanism regulating the response to Tam (39). Of note, aromatase overexpression, leading to increased androgen conversion to estrogens, also restored tamsensitivity (40).

Aromatase inhibitors (AIs), like anastrozole, letrozole and exemestane, constitute first-line treatment for ER-positive breast tumors in post-menopausal women (41). However, as with tamoxifen, an increasing number of patients do not respond to recurrent treatment with AIs making the development of novel biomarkers that may predict responsiveness a necessity. In this vein, AR-induced signaling may serve as a legitimate resistance mechanism due to its frequent expression in $\mathrm{BrCa}$ cells (9), strong co-expression with ER (42), as well as cross-talk with both ER $\alpha$ and IGF$1 \mathrm{R}$ signaling $(18,20)$.

Results from engineered estrogen-responsive MCF-7 cells overexpressing both AR and aromatase showed resistance to the inhibitory effect of anastrazol in contrast to the non-AR overexpressing cells (40). Anastrozole was unable to fully inhibit ER $\alpha$ signaling in AR-overexpressing cells, a notice that might be of clinical importance since tamoxifen- and/or AIresistant $\mathrm{BrCa}$ cells endogenously overexpress AR (40). Immunohistochemical analysis of primary versus recurrent $\mathrm{BrCa}$ lesions showed decreased ER and PR, but increased AR expression, in AI-treated recurrent lesions, suggesting an AR dependent growth of AI-resistant lesions (43). Furthermore, in vitro models simulating the $\mathrm{BrCa}$ microenvironment during AI-treatment (steroids-free, testosterone supplemented media), confirmed an AR-dependent, ER-independent pattern of growth. These results suggested that a subset of patients with AI resistance may benefit from treatment with AR-inhibitors (43). Of interest, Hole et al. showed that both letrozole and exemestane were able to inhibit testosterone-stimulated growth of AI-resistant cell lines. In addition, fulvestrant, an ER $\alpha$ antagonist, was able to fully abrogate testosterone-stimulated as well as the basal growth of the same cell lines (44), suggesting that testosterone acted primarily via ER $\alpha$ pathway via its conversion to $\mathrm{E} 2$, underscoring the importance of local sex hormone conversion.

\section{Cross-talk of AR with other Molecules/ Pathways in Breast Cancer}

AR signaling has also cross-talks with other molecules that already have been tested as potential biological targets in clinical trials. AR activation induces ERK phosphorylation through an Erbb2 (HER2)-dependent pathway (45). In contrast to androgen treatments which cause transient phosphorylation of ERK, addition of Erbb2 inhibition to these, lead to 
permanent ERK phosphorylation, which has been suggested to negatively impact tumor growth (46), probably via negative feedback-loop mechanisms. Consequently, therapeutic regimens leading to persistent ERK phosphorylation in combination with AR inhibitors were highlighted as potential therapeutic options in molecular apocrine $\mathrm{BrCa}$, a subcategory of $\mathrm{ER}^{-}$breast tumors which express AR. Simultaneous treatment of BrCa cell line MDA-MB-453 with flutamide, a non-steroidal anti-androgen, and PM-20, a Cdc25A phosphatase inhibitor, revealed synergy between these drugs as shown by growth inhibition and down-regulation of steroid response genes (47). Furthermore, xenograft tumors in NOD/SCID mice using MDA-MB-453, as an in vivo molecular apocrine BrCa model, also showed that combinational therapy with flutamide and PM-20 led to decreased tumor growth, lower tumor cellularity and proliferation index (47).

In addition to ERK, correlation with AKT pathway has also been suggested for AR signaling. AR expression has been associated with $P I 3 K$ activating mutations, while increased mTOR activity and PIK3CA mutant TNBC tumors are more likely to have higher AR expression $(48,49)$. Moreover, combinational therapies targeting both PI3k and AR have shown additive anti-tumor effects in in vitro and in vivo models of $\mathrm{AR}^{+}$TNBC tumors alluding to the potential clinical significance of this regimen in that disease subgroup (50).

As described above, the balance between androgens and estrogens in the tumor microenvironment plays a key role in the progression of the disease. A growing body of experimental studies point to the cross-talk between AR and estrogens. Among others it has been suggested that AR can directly bind to ER $\alpha$ opposing its action (51). In accordance to studies showing that AR overexpression may be associated with down-regulation of the prot-oncogene Myc (52), simultaneous administration of $\mathrm{E} 2$ and testosterone in vivo resulted in inhibition of the MYC which is usually activated by estrogens (17). In addition to $\mathrm{ER} \alpha, \mathrm{AR}$ may inhibit growth of $\mathrm{BrCa}$ cell lines via ER- $\beta$ up-regulation (53). One of the most widely studied genes in $\mathrm{BrCa}$ biology is the breast cancer 1 (BRCA1), mutations of which have been correlated with the development of the disease. It has been shown that BRCA1 may act both as an inhibitor of estrogen signaling $(54,55)$, as well as a co-activator of AR signaling $(18,56)$.

\section{AR as a Potential Biomarker in Breast Tumors}

$\mathrm{AR}$ is expressed in more than $70 \%$ of primary $\mathrm{BrCa}$, more frequently compared to ER or PR $(42,57)$, although its expression is usually correlated with these two receptors (42, 58) and has been suggested as a prognostic factor of the disease with dichotomous outcomes depending on the current tumor microenvironment $(10,11,59)$. AR expression is higher in $\mathrm{ER}^{+}$tumors (60), with a mean expression of $74.8 \%$ in contrast to $\mathrm{ER}^{-}$tumors where it is estimated at approximately $31.8 \%$ of cases (11).

A wealth body of evidence has suggested $\mathrm{AR}$ as an independent prognostic factor in $\mathrm{ER}^{+} \mathrm{BrCa}$, positively associated with favorable outcomes (time to relapse, disease free survival as well as overall survival) (61-63). AR expression has also been associated with favorable clinicopathological features of the disease, such as lower tumor grade, smaller tumor size and negative lymph-node metastasis (42, 58), as well as, older age at diagnosis (63). Mechanistically, these observations may be explained by the AR-induced inhibitory effects of androgens on estrogendependent tumor growth (8).

Estrogen status seems to play a major role in determining the prognostic significance of AR, since the same studies are not supportive for any association between AR positivity and better outcomes in ER- tumors $(62,63)$. The high histological and molecular diversity of the heterogeneous diseases comprising $\mathrm{ER}^{-} \mathrm{BrCa}$ may partially explain the inconclusive results regarding the prognostic value of $A R$ in this molecular subtype of the disease (49). In addition, in the absence of ER (ER-tumors), testosterone may preferentially be metabolized into DHT rather than E2, leading to more potent ARstimulation $(8,16,17)$. On the other hand, AR has been associated with HER-2 overexpression in ER ${ }^{-}$tumors (63). Further studies are warranted to elucidate if this might be of translational significance in anti-androgen/anti-HER2 combinational approaches and whether AR may serve as a legitimate biomarker predicting response to anti-HER2 therapeutics in $\mathrm{ER}^{-}$tumors.

More importantly, AR may serve as a marker predicting response to standard chemotherapeutic regimens in the most difficult to treat and frequently relapsing subgroup of the disease, TNBCs. Of note, ATP-based chemotherapy response assay of tumor cells from 47 patients diagnosed with TNBC showed increased susceptibility of AR-expressing tumors to methotrexate and 5-Fluorouracil (64).

\section{AR as a Therapeutic Target: Experimental and Clinical Evidence}

Androgens have been widely used as the main hormonal therapy in the treatment of $\operatorname{BrCa}(65,66)$, but their use has faded after the introduction of tamoxifen and other antiestrogens, primarily due to their masculinizing side effects. Despite the major progress in controlling the breast malignancies, TNBC remains an incurable disease. As discussed above, depending on the hormonal status in the tumor microenvironment, AR may play a key regulatory role in BrCa progression. As such, in the absence of estrogens, AR may replace the tumor promoting effects of $E R \alpha$. Consequently, research efforts have focused in targeting the $\mathrm{AR}$ in the distinct molecular subtypes of $\mathrm{BrCa}$. 
More than 20 years ago, Birrell et al. described the effect of DHT and mibolerone, an orally active anabolic-androgenic steroid, on both AR expressing and non-expressing $\mathrm{BrCa}$ cell lines and described an AR-dependent inhibitory effect on breast cancer cell growth, reversible by treatments with antiandrogens (67).

SARMs are another class of AR targeting drugs recently being tested for their therapeutic efficacies in TNBC. SARMs show agonistic effects upon AR-binding acting locally with less side-effects compared to systemic androgen therapy. SARMs have been suggested to strongly inhibit breast tumor growth both in vitro and in vivo (68). DHT and SARMs (GTx-027 and Gtx-024), both acting as agonists of AR, were able to inhibit proliferation of MDA-MB-231 $\mathrm{BrCa}$ cells engineered to express $\mathrm{AR}$ in a molecular apocrine $\mathrm{BrCa}$ model (68). In vivo evidence from the same study showed that SARMs in addition to reducing the tumor weight by more than $90 \%$ were also able to inhibit the tumor-induced cachexia with the mice gaining 3$5 \mathrm{gr}$ of weight in 5 weeks (68). These effects of SARMS in muscle mass have also been tested in human studies including patients with cancer-related cachexia $(69,70)$.

To date, patients with TNBC are exclusively treated with chemotherapeutic agents, as their response rates to standard endocrine therapy are rather poor (71-73). Propelled by studies using stratified analysis to show that in the TNBC subgroup, but not in the other subgroups (defined by ER, PR and HER2), AR expression may predict a better disease-free survival (74), recent focus has turned towards inhibiting the AR signaling in this disease subgroup. Data however remain conflicting since AR expression among the TNBC patients varies considerably (from 0 and 53\%) as addressed by the different studies (75). A phase II clinical trial evaluating the use of bicalutamide in $\mathrm{ER}^{-} / \mathrm{PR}^{-} / \mathrm{AR}^{+}$advanced breast tumors, showed a clinical benefit rate; complete or partial response or stable disease for more than 6 months, in $19 \%$ of patients (76). Two more phase II clinical trials evaluating the efficacy of bicalutamide in $\mathrm{AR}^{+}$ TNBC are currently ongoing (NCT02353988, NCT00468715), whereas another one was terminated due to slow enrollment of patients (NCT02348281). In the same molecular subgroup of the disease, results from a phase II clinical trial of enzalutamide, are also supportive for a $35 \%$ clinical benefit rate at 16 weeks, $29 \%$ at 24 weeks and a mean progression free survival of 14 weeks (77). Two more phase II trials of enzalutamide in TNBC/AR ${ }^{+}$subjects (NCT01889238) or in $\mathrm{HER}^{+} / \mathrm{AR}^{+}$locally advanced or metastatic breast cancer patients in combination with trastuzumab (NCT02091960) are currently ongoing.

Following the promising experimental evidence, the efficacy of AR targeting in ER+ tumors, primary or metastatic, resistant to conventional endocrine therapy (SERMs, aromatase inhibitors) has also been tested (78). In the presence of a malfunctioning $\mathrm{ER} \alpha, \mathrm{AR}$ becomes the primary mediator of cell growth (39), rendering blockade of the androgen-AR axis an intriguing target for the anti-hormonal resistant $\mathrm{ER}^{+} / \mathrm{AR}^{+}$ tumors. In this vein, a phase I/II trial of abiraterone acetate, an inhibitor of adrenal androgen synthesis through CYP17 blockade, in postmenopausal women with advanced or metastatic $\mathrm{BrCa}$ has recently been completed (NCT00755885) with results pending publication. In another ongoing trial (NCT01381874), abiraterone is being evaluated as combinational therapy with prednisone with or without exemestane in postmenopausal women with $\mathrm{ER}^{+}$metastatic breast tumors who have already been treated with aromatase inhibitors. Interestingly, the same compound is currently evaluated in molecular apocrine breast cancer subjects (NCT01842321). More advanced phase clinical trials, in selected population subgroups, may identify AR as a legitimate target in endocrine resistant and triple negative breast tumors.

\section{Conclusion}

The significance of AR expression as a predictive biomarker in breast tumors remains unclear. Several reasons may account for the contradictory results addressed, including different methodological approaches, disease heterogeneity, lack of common cut off points on what is considered positive or negative AR expression, distinct population subgroups analysis etc. Although several issues need to be elucidated, the era of AR signaling in $\mathrm{BrCa}$ research remains imperishable.

The perspective of targeting a commonly expressed hormone receptor, in otherwise treatment unresponsive breast tumors is certainly attractive. The interplay between androgens and estrogens in the breast cancer micro-environment is of major importance in the development and progression of the disease. In the presence of ER $\alpha, A R$ may act as a tumor suppressor by inhibiting the ER $\alpha$ induced effects, whereas in the absence of estrogens, AR may act as an ER $\alpha$ mimic and thus serve as an oncogene (79). In this vein, both AR agonists and antagonists could serve as therapeutic regimens in the different molecular subtypes of the disease. With the limited to no treatment modalities available for the treatment of TNBC, a growing era of developing novel anti-androgens has emerged as potential therapeutic agents. To date, experimental and clinical evidence has shown some early promising results. However, more studies are needed to shed more light in the complex interactions of $\mathrm{AR}$ with other molecules in $\mathrm{BrCa}$, and identify novel biomarkers that will predict population subgroups that may benefit from anti-androgen approaches.

\section{References}

1 Siegel RL, Miller KD and Jemal A: Cancer statistics, 2017. CA Cancer J Clin 67: 7-30, 2017.

2 Perou CM, Sørlie T, Eisen MB, van de Rijn M, Jeffrey SS, Rees CA, Pollack JR, Ross DT, Johnsen H, Akslen LA, Fluge O, Pergamenschikov A, Williams C, Zhu SX, Lønning PE, Børresen-Dale AL, Brown PO and Botstein D: Molecular portraits of human breast tumours. Nature 406: 747-752, 2000. 
3 Sørlie T, Perou CM, Tibshirani R, Aas T, Geisler S, Johnsen H, Hastie T, Eisen MB, van de Rijn M, Jeffrey SS, Thorsen T, Quist $\mathrm{H}$, Matese JC, Brown PO, Botstein D, Lønning PE and Børresen-Dale AL: Gene expression patterns of breast carcinomas distinguish tumor subclasses with clinical implications. Proc Natl Acad Sci USA 98: 10869-10874, 2001.

4 Early Breast Cancer Trialists' Collaborative Group (EBCTCG): Effects of chemotherapy and hormonal therapy for early breast cancer on recurrence and 15-year survival: an overview of the randomised trials. The Lancet 365: 1687-1717, 2005.

5 Jones KL and Buzdar AU: Evolving novel anti-HER2 strategies. Lancet Oncol 10: 1179-1187, 2009.

6 Rahim B and O'Regan R: AR Signaling in Breast Cancer. Cancers 9, 2017. doi: 10.3390/cancers9030021. [Epub ahead of print].

7 Denkert C, Liedtke C, Tutt A and von Minckwitz G: Molecular alterations in triple-negative breast cancer-the road to new treatment strategies. Lancet 389(10087): 2430-2442, 2016.

8 Hickey TE, Robinson JLL, Carroll JS and Tilley WD: Minireview: The androgen receptor in breast tissues: growth inhibitor, tumor suppressor, oncogene? Mol Endocrinol 26: 1252-1267, 2012.

9 Collins LC, Cole KS, Marotti JD, Hu R, Schnitt SJ and Tamimi RM: Androgen receptor expression in breast cancer in relation to molecular phenotype: results from the Nurses' Health Study. Mod Pathol 24: 924-931, 2011.

$10 \mathrm{Qu}$ Q, Mao Y, Fei X and Shen K: The impact of androgen receptor expression on breast cancer survival: a retrospective study and meta-analysis. PloS One 8: e82650, 2013.

11 Vera-Badillo FE, Templeton AJ, de Gouveia P, Diaz-Padilla I, Bedard PL, Al-Mubarak M, Seruga B, Tannock IF, Ocana A and Amir E: Androgen Receptor Expression and Outcomes in Early Breast Cancer: A systematic review and meta-analysis. JNCI J Natl Cancer Inst 106: djt319-djt319, 2014.

12 Wang C, Pan B, Zhu H, Zhou Y, Mao F, Lin Y, Xu Q and Sun $\mathrm{Q}$ : Prognostic value of androgen receptor in triple negative breast cancer: A meta-analysis. Oncotarget 7: 46482-46491, 2016.

13 McNamara KM and Sasano H: The intracrinology of breast cancer. J Steroid Biochem Mol Biol 145: 172-178, 2015.

14 Burger HG: Androgen production in women. Fertil Steril 77(Suppl 4): S3-5, 2002.

15 Labrie F, Luu-The V, Labrie C, Bélanger A, Simard J, Lin S-X and Pelletier G: Endocrine and intracrine sources of androgens in women: Inhibition of breast cancer and other roles of androgens and their precursor dehydroepiandrosterone. Endocr Rev 24: 152-182, 2003.

16 Dimitrakakis C, Zhou J, Wang J, Belanger A, LaBrie F, Cheng C, Powell D and Bondy C: A physiologic role for testosterone in limiting estrogenic stimulation of the breast. Menopause N Y N 10: 292-298, 2003.

17 Zhou J, Ng S, Adesanya-Famuiya O, Anderson K and Bondy CA: Testosterone inhibits estrogen-induced mammary epithelial proliferation and suppresses estrogen receptor expression. FASEB J Off Publ Fed Am Soc Exp Biol 14: 1725-1730, 2000.

18 Yeh S: Abnormal mammary gland development and growth retardation in female mice and MCF7 breast cancer cells lacking androgen receptor. J Exp Med 198: 1899-1908, 2003.

19 Gao YR (Ellen), Walters KA, Desai R, Zhou H, Handelsman DJ and Simanainen $\mathrm{U}$ : Androgen receptor inactivation resulted in acceleration in pubertal mammary gland Growth, upregulation of ER $\alpha$ expression, and $\mathrm{Wnt} / \beta$-Catenin signaling in female mice. Endocrinology 155: 4951-4963, 2014.

20 Chang C, Lee SO, Wang R-S, Yeh S and Chang T-M: Androgen Receptor (AR) physiological roles in male and female reproductive systems: lessons learned from AR-knockout mice lacking AR in selective cells. Biol Reprod 89: 21-21, 2013.

21 Peters AA, Ingman WV, Tilley WD and Butler LM: Differential effects of exogenous androgen and an androgen receptor antagonist in the peri- and post pubertal murine mammary gland. Endocrinology 152: 3728-3737, 2011.

22 Poulin R, Baker D and Labrie F: Androgens inhibit basal and estrogen-induced cell proliferation in the ZR-75-1 human breast cancer cell line. Breast Cancer Res Treat 12: 213-225, 1988.

23 Rothman MS, Carlson NE, Xu M, Wang C, Swerdloff R, Lee P, Goh VHH, Ridgway EC and Wierman ME: Reexamination of testosterone, dihydrotestosterone, estradiol and estrone levels across the menstrual cycle and in postmenopausal women measured by liquid chromatography-tandem mass spectrometry. Steroids 76: 177-182, 2011.

24 Zardavas D, Irrthum A, Swanton C and Piccart M: Clinical management of breast cancer heterogeneity. Nat Rev Clin Oncol 12: 381-394, 2015.

25 Hickey TE, Irvine CM, Dvinge H, Tarulli GA, Hanson AR, Ryan NK, Pickering MA, Birrell SN, Hu DG, Mackenzie PI, Russell R, Caldas C, Raj GV, Dehm SM, Plymate SR, Bradley RK, Tilley WD and Selth LA: Expression of androgen receptor splice variants in clinical breast cancers. Oncotarget 6(42): 4472844744, 2015.

26 Gottlieb B, Alvarado C, Wang C, Gharizadeh B, Babrzadeh F, Richards B, Batist G, Basik M, Beitel LK and Trifiro M: Making sense of intratumor genetic heterogeneity: Altered frequency of androgen receptor CAG repeat length variants in breast cancer tissues. Hum Mutat 34: 610-618, 2013.

27 Giguère Y, Dewailly E, Brisson J, Ayotte P, Laflamme N, Demers A, Forest VI, Dodin S, Robert J and Rousseau F: Short polyglutamine tracts in the androgen receptor are protective against breast cancer in the general population. Cancer Res 61: 5869-5874, 2001.

28 Rajender S, Francis A, Pooja S, Krupakar N, Surekha D, Reddy G, Rao DR, Rao L, Ramachandra S, Vishnupriya S, Ramalingam $\mathrm{K}$, Satyamoorthy $\mathrm{K}$ and Thangaraj K: CAG repeat length polymorphism in the androgen receptor gene and breast cancer risk: data on Indian women and survey from the world. Breast Cancer Res Treat 127: 751-760, 2011.

29 Hao Y, Montiel R, Li B, Huang E, Zeng L and Huang Y: Association between androgen receptor gene CAG repeat polymorphism and breast cancer risk: a meta-analysis. Breast Cancer Res Treat 124: 815-820, 2010.

30 Lundin KB, Henningson M, Hietala M, Ingvar C, Rose C and Jernström H: Androgen receptor genotypes predict response to endocrine treatment in breast cancer patients. Br J Cancer 105: 1676-1683, 2011.

31 Ward RD and Weigel NL: Steroid receptor phosphorylation: Assigning function to site-specific phosphorylation. BioFactors 35: 528-536, 2009.

32 Koryakina Y, Ta HQ and Gioeli D: Androgen receptor phosphorylation: biological context and functional consequences. Endocr Relat Cancer 21: T131-T145, 2014. 
33 Ren Q, Zhang L, Ruoff R, Ha S, Wang J, Jain S, Reuter V, Gerald W, Giri DD, Melamed J, Garabedian MJ, Lee P and Logan SK: Expression of androgen receptor and its phosphorylated forms in breast cancer progression. Cancer 119: 2532-2540, 2013.

34 O'Regan RM and Jordan VC: The evolution of tamoxifen therapy in breast cancer: selective oestrogen-receptor modulators and downregulators. Lancet Oncol 3: 207-214, 2002.

35 García-Becerra R, Santos N, Díaz L and Camacho J: Mechanisms of Resistance to Endocrine Therapy in Breast Cancer: Focus on signaling pathways, miRNAs and genetically based resistance. Int J Mol Sci 14: 108-145, 2012.

36 Benz CC, Scott GK, Sarup JC, Johnson RM, Tripathy D, Coronado E, Shepard HM and Osborne CK: Estrogendependent, tamoxifen-resistant tumorigenic growth of MCF-7 cells transfected with HER2/neu. Breast Cancer Res Treat 24: 85-95, 1992

37 Christopoulos PF, Msaouel P and Koutsilieris M: The role of the insulin-like growth factor- 1 system in breast cancer. Mol Cancer 14: 43, 2015.

38 Cui Y, Parra I, Zhang M, Hilsenbeck SG, Tsimelzon A, Furukawa T, Horii A, Zhang Z-Y, Nicholson RI and Fuqua SAW: Elevated expression of mitogen-activated protein kinase phosphatase 3 in breast tumors: a mechanism of tamoxifen resistance. Cancer Res 66: 5950-5959, 2006.

39 De Amicis F, Thirugnansampanthan J, Cui Y, Selever J, Beyer A, Parra I, Weigel NL, Herynk MH, Tsimelzon A, Lewis MT, Chamness GC, Hilsenbeck SG, Andò $S$ and Fuqua SAW: Androgen receptor overexpression induces tamoxifen resistance in human breast cancer cells. Breast Cancer Res Treat 121: 1$11,2010$.

40 Rechoum Y, Rovito D, Iacopetta D, Barone I, Andò S, Weigel NL, O'Malley BW, Brown PH and Fuqua SAW: AR collaborates with ER $\alpha$ in aromatase inhibitor-resistant breast cancer. Breast Cancer Res Treat 147: 473-485, 2014.

41 Goldhirsch A, Wood WC, Coates AS, Gelber RD, Thurlimann B, Senn H-J and Panel members: Strategies for subtypes-dealing with the diversity of breast cancer: highlights of the St Gallen International Expert Consensus on the Primary Therapy of Early Breast Cancer 2011. Ann Oncol 22: 17361747, 2011.

42 Ogawa Y, Hai E, Matsumoto K, Ikeda K, Tokunaga S, Nagahara H, Sakurai K, Inoue T and Nishiguchi Y: Androgen receptor expression in breast cancer: relationship with clinicopathological factors and biomarkers. Int J Clin Oncol 13: 431-435, 2008.

43 Fujii R, Hanamura T, Suzuki T, Gohno T, Shibahara Y, Niwa T, Yamaguchi Y, Ohnuki K, Kakugawa Y, Hirakawa H, Ishida T, Sasano H, Ohuchi N and Hayashi S: Increased androgen receptor activity and cell proliferation in aromatase inhibitor-resistant breast carcinoma. J Steroid Biochem Mol Biol 144: 513-522, 2014.

44 Hole S, Pedersen A, Hansen S, Lundqvist J, Yde C and Lykkesfeldt A: New cell culture model for aromatase inhibitorresistant breast cancer shows sensitivity to fulvestrant treatment and cross-resistance between letrozole and exemestane. Int J Oncol 46: 1481-1490, 2015.

45 Chia KM, Liu J, Francis GD and Naderi A: A feedback loop between androgen receptor and ERK signaling in estrogen receptor-negative breast Cancer. Neoplasia 13: 154-166, 2011.
46 Naderi A and Hughes-Davies L: A functionally significant crosstalk between androgen receptor and ErbB2 pathways in estrogen receptor negative breast cancer. Neoplasia N Y N 10: 542-548, 2008.

47 Naderi A and Liu J: Inhibition of androgen receptor and Cdc25A phosphatase as a combination targeted therapy in molecular apocrine breast cancer. Cancer Lett 298: 74-87, 2010.

48 Gonzalez-Angulo AM, Stemke-Hale K, Palla SL, Carey M, Agarwal R, Meric-Berstam F, Traina TA, Hudis C, Hortobagyi GN, Gerald WL, Mills GB and Hennessy BT: Androgen receptor levels and association with PIK3CA mutations and prognosis in breast cancer. Clin Cancer Res 15: 2472-2478, 2009.

49 Lehmann BD, Bauer JA, Chen X, Sanders ME, Chakravarthy AB, Shyr Y and Pietenpol JA: Identification of human triple-negative breast cancer subtypes and preclinical models for selection of targeted therapies. J Clin Invest 121: 2750-2767, 2011.

50 Lehmann BD, Bauer JA, Schafer JM, Pendleton CS, Tang L, Johnson KC, Chen X, Balko JM, Gómez H, Arteaga CL, Mills GB, Sanders ME and Pietenpol JA: PIK3CA mutations in androgen receptor-positive triple negative breast cancer confer sensitivity to the combination of PI3K and androgen receptor inhibitors. Breast Cancer Res 16: 406, 2014.

51 Panet-Raymond V, Gottlieb B, Beitel LK, Pinsky L and Trifiro MA: Interactions between androgen and estrogen receptors and the effects on their transactivational properties. Mol Cell Endocrinol 167: 139-150, 2000.

52 Bièche I, Parfait B, Tozlu S, Lidereau R and Vidaud M: Quantitation of androgen receptor gene expression in sporadic breast tumors by real-time RT-PCR: evidence that MYC is an AR-regulated gene. Carcinogenesis 22: 1521-1526, 2001.

53 Rizza P, Barone I, Zito D, Giordano F, Lanzino M, De Amicis F, Mauro L, Sisci D, Catalano S, Dahlman Wright K, Gustafsson $\mathrm{J}$-A and Andò S: Estrogen receptor beta as a novel target of androgen receptor action in breast cancer cell lines. Breast Cancer Res BCR 16: R21, 2014.

54 Fan S, Wang J, Yuan R, Ma Y, Meng Q, Erdos MR, Pestell RG, Yuan F, Auborn KJ, Goldberg ID and Rosen EM: BRCA1 inhibition of estrogen receptor signaling in transfected cells. Science 284: 1354-1356, 1999.

55 Zheng L, Annab LA, Afshari CA, Lee WH and Boyer TG: BRCA1 mediates ligand-independent transcriptional repression of the estrogen receptor. Proc Natl Acad Sci USA 98: 95879592, 2001.

56 Park JJ, Irvine RA, Buchanan G, Koh SS, Park JM, Tilley WD, Stallcup MR, Press MF and Coetzee GA: Breast cancer susceptibility gene 1 (BRCAI) is a coactivator of the androgen receptor. Cancer Res 60: 5946-5949, 2000.

57 Cimino-Mathews A, Hicks JL, Illei PB, Halushka MK, Fetting JH, De Marzo AM, Park BH and Argani P: Androgen receptor expression is usually maintained in initial surgically resected breast cancer metastases but is often lost in end-stage metastases found at autopsy. Hum Pathol 43: 1003-1011, 2012.

58 Sultana A, Idress R, Naqvi ZA, Azam I, Khan S, Siddiqui AA and Lalani E-N: Expression of the androgen receptor, pakt, and ppten in breast cancer and their potential in prognostication. Transl Oncol 7: 355-362, 2014.

59 Zhang L, Fang C, Xu X, Li A, Cai Q and Long X: Androgen receptor, egfr, and brcal as biomarkers in triple-negative breast cancer: A Meta-Analysis. BioMed Res Int 2015: 357485,2015 
60 McNamara KM, Moore NL, Hickey TE, Sasano H and Tilley WD: Complexities of androgen receptor signalling in breast cancer. Endocr Relat Cancer 21: T161-T181, 2014.

61 Castellano I, Allia E, Accortanzo V, Vandone AM, Chiusa L, Arisio R, Durando A, Donadio M, Bussolati G, Coates AS, Viale $\mathrm{G}$ and Sapino A: Androgen receptor expression is a significant prognostic factor in estrogen receptor positive breast cancers. Breast Cancer Res Treat 124: 607-617, 2010.

62 Hu R, Dawood S, Holmes MD, Collins LC, Schnitt SJ, Cole K, Marotti JD, Hankinson SE, Colditz GA and Tamimi RM: Androgen receptor expression and breast cancer survival in postmenopausal women. Clin Cancer Res 17: 1867-1874, 2011.

63 Park S, Koo JS, Kim MS, Park HS, Lee JS, Lee JS, Kim SI, Park $\mathrm{B}-\mathrm{W}$ and Lee KS: Androgen receptor expression is significantly associated with better outcomes in estrogen receptor-positive breast cancers. Ann Oncol 22: 1755-1762, 2011.

64 Koo JS, Jung W and Jeong J: The predictive role of e-cadherin and androgen receptor on in vitro chemosensitivity in triplenegative breast cancer. Jpn J Clin Oncol 39: 560-568, 2009.

65 Goldenberg IS: Testosterone propionate therapy in breast cancer. JAMA 188: 1069-1072, 1964.

66 Tormey DC, Lippman ME, Edwards BK and Cassidy JG: Evaluation of tamoxifen doses with and without fluoxymesterone in advanced breast cancer. Ann Intern Med 98: 139-144, 1983.

67 Birrell SN, Bentel JM, Hickey TE, Ricciardelli C, Weger MA, Horsfall DJ and Tilley WD: Androgens induce divergent proliferative responses in human breast cancer cell lines. J Steroid Biochem Mol Biol 52: 459-467, 1995.

68 Narayanan R, Ahn S, Cheney MD, Yepuru M, Miller DD, Steiner MS and Dalton JT: Selective androgen receptor modulators (SARMs) negatively regulate triple-negative breast cancer growth and epithelial: mesenchymal stem cell signaling. PLoS One 9: e103202, 2014.

69 Dalton JT, Barnette KG, Bohl CE, Hancock ML, Rodriguez D, Dodson ST, Morton RA and Steiner MS: The selective androgen receptor modulator GTx-024 (enobosarm) improves lean body mass and physical function in healthy elderly men and postmenopausal women: results of a double-blind, placebo-controlled phase II trial. J Cachexia Sarcopenia Muscle 2: 153-161, 2011.

70 Dobs AS, Boccia RV, Croot CC, Gabrail NY, Dalton JT, Hancock ML, Johnston MA and Steiner MS: Effects of enobosarm on muscle wasting and physical function in patients with cancer: a double-blind, randomised controlled phase 2 trial. Lancet Oncol 14: 335-345, 2013.

71 Bauer KR, Brown M, Cress RD, Parise CA and Caggiano V: Descriptive analysis of estrogen receptor (ER)-negative, progesterone receptor (PR)-negative, and HER2-negative invasive breast cancer, the so-called triple-negative phenotype: a population-based study from the California cancer Registry. Cancer 109: 1721-1728, 2007.
72 Kassam F, Enright K, Dent R, Dranitsaris G, Myers J, Flynn C, Fralick M, Kumar R and Clemons M: Survival outcomes for patients with metastatic triple-negative breast cancer: implications for clinical practice and trial design. Clin Breast Cancer 9: 29-33, 2009.

73 Dent R, Trudeau M, Pritchard KI, Hanna WM, Kahn HK, Sawka CA, Lickley LA, Rawlinson E, Sun P and Narod SA: Triplenegative breast cancer: clinical features and patterns of recurrence. Clin Cancer Res Off J Am Assoc Cancer Res 13: 4429-4434, 2007.

74 Loibl S, Müller BM, von Minckwitz G, Schwabe M, Roller M, Darb-Esfahani S, Ataseven B, du Bois A, Fissler-Eckhoff A, Gerber B, Kulmer U, Alles J-U, Mehta K and Denkert C: Androgen receptor expression in primary breast cancer and its predictive and prognostic value in patients treated with neoadjuvant chemotherapy. Breast Cancer Res Treat 130: 477-487, 2011.

75 McNamara KM, Yoda T, Takagi K, Miki Y, Suzuki T and Sasano $\mathrm{H}$ : Androgen receptor in triple negative breast cancer. J Steroid Biochem Mol Biol 133: 66-76, 2013.

76 Gucalp A, Tolaney S, Isakoff SJ, Ingle JN, Liu MC, Carey LA, Blackwell K, Rugo H, Nabell L, Forero A, Stearns V, Doane AS, Danso M, Moynahan ME, Momen LF, Gonzalez JM, Akhtar A, Giri DD, Patil S, Feigin KN, Hudis CA, Traina TA and on behalf of the Translational Breast Cancer Research Consortium (TBCRC 011): Phase II Trial of Bicalutamide in Patients with Androgen Receptor-Positive, Estrogen Receptor-Negative Metastatic Breast Cancer. Clin Cancer Res 19: 5505-5512, 2013.

77 Traina TA, Miller K, Yardley DA, O’Shaughnessy J, Cortes J, Awada A, Kelly CM, Trudeau ME, Schmid P, Gianni L, GarcíaEstevez L, Nanda R, Ademuyiwa FO, Chan S, Steinberg JL, Blaney ME, Tudor IC, Uppal H, Peterson AC and Hudis CA: Results from a phase 2 study of enzalutamide (ENZA), an androgen receptor (AR) inhibitor, in advanced $\mathrm{AR}+$ triplenegative breast cancer (TNBC). J Clin Oncol 33(15): 1003, 2015.

78 Agrawal A, Robertson JFR and Cheung KL: "Resurrection of clinical efficacy" after resistance to endocrine therapy in metastatic breast cancer. World J Surg Oncol 4: 40, 2006.

79 Hickey TE, Robinson JLL, Carroll JS and Tilley WD: Minireview: The androgen receptor in breast tissues: growth inhibitor, tumor suppressor, oncogene? Mol Endocrinol 26: 1252-1267, 2012. 